\title{
Structural brain abnormalities in adult males with clefts of the lip and/or palate
}

Peg Nopoulos, $M D^{1}$, Stephanie Berg, BA ${ }^{1}$, John Canady, $M D^{2}$, Lynn Richman, PhD ${ }^{3}$, Duane Van Demark, PhD ${ }^{2}$, and Nancy C. Andreasen, $M D, P h D^{1}$

\begin{abstract}
Purpose: To evaluate brain morphology of adult males with nonsyndromic clefts of the lip and/or palate (NSCLP)
in comparison to a matched healthy control group. Methods: Brain structure was measured using quantitative analysis of magnetic resonance images. Results: Subjects with NSCLP had significant abnormalities in brain morphology consisting of abnormally enlarged anterior regions of the cerebrum, and decreased volumes of the posterior cerebrum and cerebellum. Overall, the most severely affected region was the left temporal lobe. Furthermore, these structural abnormalities were directly related to cognitive dysfunction. Conclusions: These findings highlight the important relationship and interplay between face and brain development. Genet Med 2002:
\end{abstract} 4(1):1-9.

Key Words: magnetic resonance imaging, brain structure, oral clefts, brain development

Oral clefts compose a significant component of morbid human birth defects. These oral clefts are developmental craniofacial abnormalities that result, at least in part, from a failure of neural crest cells to migrate properly. As a group, $70 \%$ of clefting disorders are composed of those that are isolated to facial clefts only (nonsyndromic), and 30\% are those in which the facial cleft is part of a well-defined syndrome of additional anomalies. ${ }^{1}$ Nonsyndromic clefts of the lip and/or palate (NSCLP) occur in approximately 1 per 1,000 livebirths among Caucasians and are further divided anatomically into clefts of the lip and/or palate (CLP) and clefts of the palate only (CPO).

In addition to the facial cleft, many patients also suffer from cognitive impairment. In syndromic clefts, this impairment is often severe. In NSCLP, the cognitive impairment is less severe but the functional consequences of these deficits should not be underestimated. Specifically, children with NSCLP have been shown to have a lower IQ compared with matched controls. ${ }^{2}$ In addition to this generalized deficit, many patients also have abnormalities in language function. ${ }^{3,4}$ This language deficit is severe enough to be designated as a reading disability in as many as $35 \%$ of this population. ${ }^{5}$

Many have considered these cognitive abnormalities as "secondary" to factors such as hearing deficits, speech deficits, or both. ${ }^{6,7}$ Yet other reports have shown that cognitive skills are not significantly affected by peripheral deficiency in speech and hearing. ${ }^{8,9}$ More likely is the notion that abnormal brain function (cognitive impairment) is not secondary to external

\footnotetext{
From the ${ }^{1}$ Departments of Psychiatry, ${ }^{2}$ Otolaryngology, and ${ }^{3}$ Pediatrics, University of Iowa Hospitals and Clinics, Iowa City, Iowa.

Peg Nopoulos, MD, 1-180 MEB, Department of Psychiatry, University of Iowa Hospitals and Clinics, Iowa City, IA 52242.

Received: September 10, 2001.
}

Accepted: November 1, 2001. factors but primary to abnormal brain structure. In the case of NSCLP, this most likely would be due to abnormalities in brain development.

The development of the brain and face are intimately related in both normal and pathologic conditions. ${ }^{10,11}$ This relationship is such a well-known phenomenon that dysmorphologists have coined the phrase "the face reflects the brain." Therefore, that there may be abnormal brain development accompanying an abnormality in facial development should not be surprising. However, the systematic study of structural brain abnormalities in patients with NSCLP (and the functional consequences thereof) has been almost completely overlooked.

Advances in neuroimaging techniques using magnetic resonance imaging (MRI) allows for sophisticated methods in quantifying human brain structure. Using state of the art postprocessing procedure, the current study is the first to evaluate brain morphology in subjects with NSCLP. A published preliminary analysis on the first 30 subjects in the study (15 patients vs. 15 controls) indicated significant abnormalities in brain morphology with enlargement of anterior regions of the cerebrum and decrement in size of the posterior cerebrum and of the cerebellum. ${ }^{12}$ The current report documents the result of the entire sample of 92 ( 46 subjects vs. 46 controls) with more extensive regional analysis as well as evaluation of tissue type (gray matter and white matter volumes).

\section{METHODS}

\section{Subjects}

A total of 46 adult males with NSCLP were recruited from the University of Iowa Cleft Lip and Palate Registry. Medical records were reviewed to verify and document cleft status, including cleft region (lip only, cleft lip and palate, palate only), side of the cleft (right, left, median, or bilateral), and the degree 
of clefting (complete, partial, microform). All patients had been previously examined by a trained medical geneticist to rule out congenital syndromes. Three subjects were found to have lip pits in addition to oral clefts. The occurrence of lip pits and isolated clefts of the lip and/or palate is referred to as Van der Woude syndrome. However, because this syndrome is manifested only in oral clefts and lip pits (no other congenital defects), these three patients were retained in the sample. There were a total of 32 subjects with CLP (11 with bilateral clefting, 18 with left unilateral clefting, 3 with right unilateral clefting) and 14 subjects with CPO.

The comparison group was obtained through a registry of healthy controls (recruited from the community) from the University of Iowa Mental Health Clinical Research Center (MH-CRC). This control group was designed to be equivalent to the clefting subjects on sex, age, parental socioeconomic status, and level of education. Reflective of the population in Iowa, all of the subjects and controls were Caucasian. After complete description of the protocol, both subject groups signed informed consent as directed by the local institutional review board. Table 1 displays the demographic data for both study groups.

Both groups were administered a battery of cognitive tests, including measures of Full Scale IQ (FSIQ), Performance IQ (PIQ), and Verbal IQ (VIQ) using the Wechsler Adult Intelligence Scale-Revised. ${ }^{13}$ A previous study details the results of the comparative analysis of cognitive tasks. ${ }^{14}$

\section{Imaging methods}

Images were obtained on a 1.5 Tesla GE Signa MR scanner. Three different sequences were acquired for each subject. T1 weighted images, using a spoiled grass sequence, were acquired with the following parameters: $1.5-\mathrm{mm}$ coronal slices, 40 -degree flip angle, 24-msec TR, 5-msec TE, $2 \mathrm{NEX}, 26-\mathrm{cm}$ field of view (FOV), and a $256 \times 192$ matrix. The PD and T2 weighted images were acquired with the following parameters: $3.0-\mathrm{mm}$ coronal slices, 36-msec TE (for PD) or 96-msec TE (for T2), 3,000-msec TR, 1 NEX, 26-cm FOV, 256 × 192 matrix, and an echo train length $=1$.

Processing of the images after acquisition was done using a locally developed family of software programs called BRAINS (acronym for Brain Research: Analysis of Images, Networks, and Systems). Details of the image analysis are published elsewhere. ${ }^{15-18}$ Briefly, a three-dimensional data set is created and the images are realigned, re-sampled, and transformed into Talairach Atlas space. ${ }^{19}$

\section{Brain volume measures}

Within the stereotactic space, boxes are assigned to specific brain regions. Intracranial volume is subdivided into brain tissue and cerebral spinal fluid (CSF). Total volume of CSF is broken down into internal CSF (includes ventricles and cisterns) and surface CSF. Brain tissue is subdivided into the cerebrum and cerebellum. The cerebrum is then divided further into its four lobes. Volumes of tissue are obtained from each region in an automated manner (see Fig. 1). This method of automated measures using a stereotactically based method has been reported by our lab and others to be efficient and accurate for cerebral lobe measures. ${ }^{20,21}$

\section{Tissue classification}

To break down the tissue volumes described above into the component parts, we used our newest method for segmentation, a fully automated method based on discriminant function analysis. This method uses data from the $\mathrm{T} 1$ and the proton density (PD)/T2 sequences (see Fig. 2). The details of this method are published elsewhere. ${ }^{22}$ Measures obtained for analysis included total cerebral gray matter volume and cerebral white matter volume. In addition, each cerebral lobe is segmented into components of gray and white matter volume.

\section{Statistical analysis}

All analyses were performed by using the SAS language with SAS STAT procedures. All brain tissue measures were analyzed using the General Linear Models Procedure. A systematic study of brain measures was used starting with the analysis of more general measures and moving through increasingly smaller portions or regions of the brain. In addition, each tissue measure was then broken down into its components of gray matter and white matter. This method created a "hierarchy" of variables, beginning with the general measures of intracranial volume, cerebral tissue volume, and cerebellar tissue volume. These were further broken down into total cerebral spinal fluid (CSF), further divided into ventricle volume and surface CSF; cerebral gray matter, further divided into surface gray matter (reflecting the volume of the cortex) and subcortical gray matter (reflecting the volume of the subcortical nuclei); cerebral white matter; cerebellar gray matter; and cerebellar white matter. Next, the cerebrum was divided into an anterior/superior region (frontal and parietal lobes) and a posterior/inferior region (temporal and occipital lobes). These regions were further divided into gray and white matter volumes.

Table 1

Demographics of sample

\begin{tabular}{|c|c|c|c|c|c|}
\hline & & $\begin{array}{c}\text { Age } \\
\text { Mean (SD) }\end{array}$ & $\begin{array}{l}\text { Parental SES } \\
\text { Mean }(\mathrm{SD})\end{array}$ & $\begin{array}{l}\text { Ratio left-handers/ } \\
\text { right-handers }\end{array}$ & $\begin{array}{c}\text { Education (years) } \\
\text { Mean (SD) }\end{array}$ \\
\hline NSCLP subjects & $(n=46)$ & $30.1(7.04)$ & $3.13(0.71)$ & $4 / 42$ & $13.8(2.09)$ \\
\hline Controls & $(n=46)$ & $28.8(7.60)$ & $2.97(0.33)$ & $8 / 38$ & $14.5(1.97)$ \\
\hline
\end{tabular}

${ }^{a}$ Parental socioeconomic status (SES) based on a modified Hollingshead scale of 1-5 with the higher the number, the lower the status. 

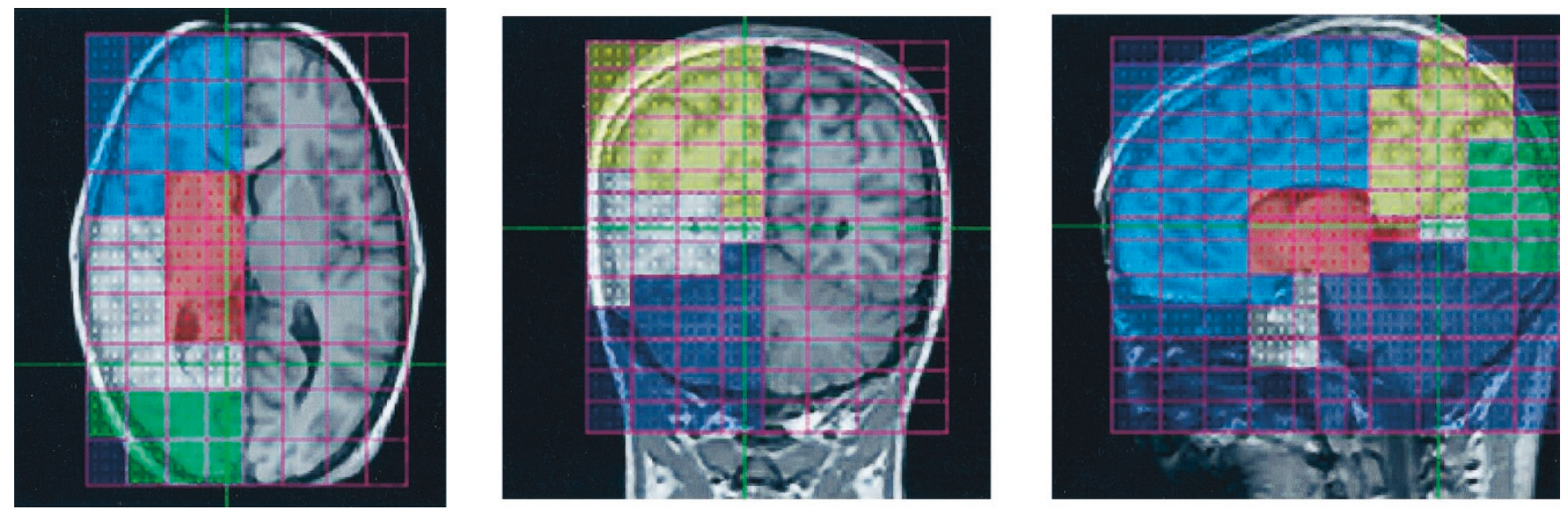

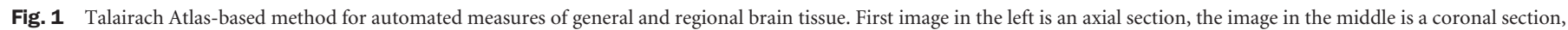
and the image on the right is a sagittal section. Blue, frontal lobe; yellow, parietal lobe; white, temporal lobe; green, occipital lobe; purple, cerebellum; red, subcortical tissue.

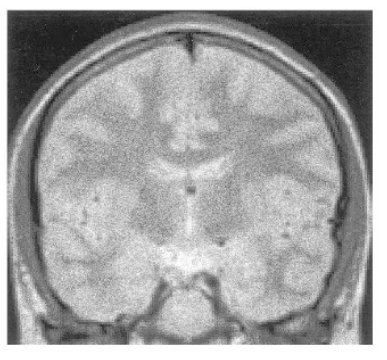

Proton Density

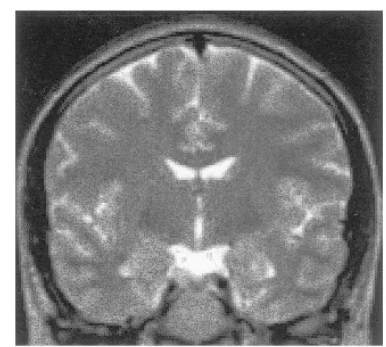

$\mathbf{T 2}$

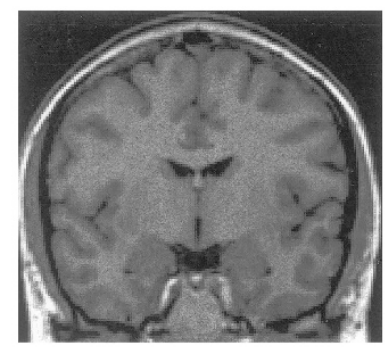

T1

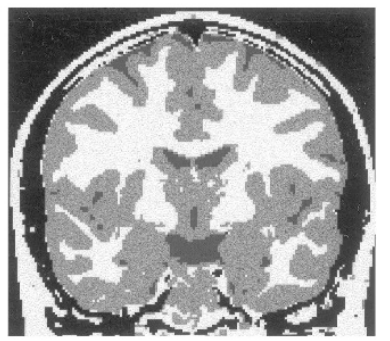

Segmented Image

Fig. 2 Tissue classification method using three separate imaging sequences (proton density, T2 and T1) to classify tissue into gray matter, white matter, and cerebral spinal fluid.

Finally, each lobe of the cerebrum (frontal, parietal, temporal, and occipital) was individually analyzed as a whole and as their component gray and white matter volumes.

The covariates used in the analyses varied with the size of the measure. That is, for the general measures, height was used as a covariate. For the tissue segmentation of the general measures and the anterior and posterior cerebral volumes analysis, intracranial volume was used as the covariate. Finally, for the smallest regions (the four cerebral lobes), total cerebral tissue volume was used as the covariate. All possible interaction terms were entered into the model but were dropped if not significant. An alpha level of 0.05 was used for significance tests, except for tests for assumptions within the general linear model, in which case an alpha of 0.10 was used. That is, if an interaction term was found to be significant at $P<0.10$, it was maintained within the model.

To investigate laterality of regional measures, repeated measures analysis of covariance (total cerebral tissue covariate) was used. To limit number of analysis and possible type I error, only those regions that had significant structural abnormalities were entered. Significant laterality was identified by a side-bydiagnosis interaction with a $P<0.05$.

\section{RESULTS}

Table 2 outlines the findings of the analysis of general measures, tissue segmentation of general measures, regions of the cerebrum, and cerebral lobes. To help gauge the magnitude of difference, effect sizes are shown in the last column. Effect size is a way of showing the size of difference between two groups based on the average intersubject variability. Effect sizes of 0.2 are considered small, of 0.5 are moderate, and those of 0.8 or greater are large. ${ }^{23}$

\section{General measures}

Subjects with NSCLP showed no significant difference from controls on measures of intracranial volume, total brain volume, or cerebral volume. Total volume of CSF was significantly decreased in subjects with NSCLP. This finding was true for both the ventricular volume as well as the volume of surface CSF. In addition, there was a significant difference between the two groups in the volume of the cerebellum with the NSCLP subjects having smaller volumes compared with controls.

\section{Tissue segmentation of general measures}

The NSCLP group showed significant differences compared with controls in regard to volumes of specific tissue types: 
Table 2

Results of analysis on general and regional brain measures

\begin{tabular}{|c|c|c|c|c|c|c|c|c|c|}
\hline & \multicolumn{3}{|c|}{ NSCLP subjects $(n=46)$} & \multicolumn{3}{|c|}{ Controls $(n=46)$} & \multirow[b]{2}{*}{$\mathrm{F}$} & \multirow[b]{2}{*}{$P$} & \multirow[b]{2}{*}{$\begin{array}{c}\text { Effect } \\
\text { size }\end{array}$} \\
\hline & Mean & SD & $\begin{array}{c}\text { Adjusted } \\
\text { mean }^{a}\end{array}$ & Mean & SD & $\begin{array}{c}\text { Adjusted } \\
\text { mean }^{a}\end{array}$ & & & \\
\hline \multicolumn{10}{|l|}{ General measures $^{b}$ (cc's) } \\
\hline Intracranial volume & 1,449 & 141 & 1,448 & 1,490 & 117 & 1,491 & 2.67 & 0.105 & 0.342 \\
\hline Total brain tissue & 1,360 & 134 & 1,359 & 1,384 & 118 & 1,385 & 1.02 & 0.315 & 0.215 \\
\hline Total CSF & 88.6 & 34.1 & 88.7 & 106.2 & 40.8 & 106 & 4.91 & 0.025 & 0.461 \\
\hline Ventricles & 13.4 & 6.49 & 13.8 & 16.3 & 6.70 & 16.3 & 4.56 & 0.035 & 0.437 \\
\hline Surface CSF & 50.3 & 27.3 & 50.4 & 63.7 & 33.0 & 63.6 & 4.36 & 0.039 & 0.437 \\
\hline Cerebral volume & 1,190 & 123 & 1,189 & 1,201 & 108 & 1,201 & 0.27 & 0.602 & 0.108 \\
\hline Cerebellar volume & 133 & 17.7 & 133 & 146 & 16.9 & 146 & 11.3 & 0.001 & 0.747 \\
\hline \multicolumn{10}{|l|}{$\begin{array}{l}\text { Tissue segmentation of general } \\
\text { measures }^{c}\left(c^{\prime} s\right)\end{array}$} \\
\hline Cerebral gray matter & 706 & 71.9 & 715 & 706 & 62.5 & 696 & 5.78 & 0.018 & 0.530 \\
\hline Surface gray matter (cortex) & 652 & 67.2 & 660 & 649 & 59.7 & 640 & 7.41 & 0.007 & 0.579 \\
\hline Subcortical gray matter & 54.0 & 7.00 & 54.5 & 56.8 & 6.13 & 56.2 & 2.07 & 0.153 & 0.308 \\
\hline Cerebral white matter & 484 & 59.4 & 492 & 494 & 61.8 & 486 & 0.088 & 0.351 & 0.191 \\
\hline Cerebellar gray matter & 97.6 & 13.9 & 98.6 & 110 & 14.3 & 109 & 15.5 & 0.0002 & 0.825 \\
\hline Cerebellar white matter & 36.3 & 7.96 & 36.7 & 35.8 & 6.20 & 35.4 & 0.083 & 0.364 & 0.195 \\
\hline \multicolumn{10}{|l|}{ Regions of cerebrum ${ }^{c}\left(\mathrm{cc}^{\prime} \mathrm{s}\right)$} \\
\hline Anterior cerebrum & 727 & 82.1 & 738 & 720 & 73.3 & 709 & 13.0 & 0.0005 & 0.775 \\
\hline Gray matter & 418 & 47.1 & 423 & 409 & 43.8 & 404 & 10.3 & 0.001 & 0.659 \\
\hline White matter & 309 & 40.2 & 314 & 310 & 40.0 & 305 & 3.45 & 0.066 & 0.393 \\
\hline Posterior cerebrum & 351 & 34.7 & 356 & 369 & 33.8 & 364 & 9.05 & 0.003 & 0.655 \\
\hline Gray matter & 224 & 22.1 & 227 & 229 & 19.4 & 226 & 0.11 & 0.735 & 0.084 \\
\hline White matter & 127 & 16.0 & 129 & 140 & 20.3 & 138 & 14.3 & 0.0003 & 0.841 \\
\hline \multicolumn{10}{|l|}{ Cerebral lobes $^{d}\left(\mathrm{cc}^{\prime} s\right)$} \\
\hline Frontal lobe & 463 & 55.9 & 465 & 460 & 49.7 & 458 & 4.88 & 0.029 & 0.451 \\
\hline Gray matter & 275 & 32.3 & 276 & 270 & 30.0 & 269 & 4.97 & 0.028 & 0.460 \\
\hline White matter & 188 & 27.3 & 189 & 190 & 26.5 & 188 & 0.00 & 0.981 & 0.070 \\
\hline Parietal lobe & 264 & 28.0 & 265 & 260 & 26.7 & 258 & 10.5 & 0.001 & 0.736 \\
\hline Gray matter & 143 & 15.6 & 143 & 139 & 15.3 & 139 & 7.86 & 0.006 & 0.486 \\
\hline White matter & 120 & 14.1 & 121 & 120 & 15.4 & 119 & 0.09 & 0.330 & 0.251 \\
\hline Temporal lobe & 227 & 22.9 & 228 & 238 & 20.6 & 237 & 18.3 & $<0.0001$ & 0.891 \\
\hline Gray matter & 153 & 14.4 & 154 & 159 & 12.9 & 158 & 9.41 & 0.002 & 0.526 \\
\hline White matter & 74.0 & 10.3 & 74.3 & 78.9 & 10.8 & 78.6 & 8.11 & 0.005 & 0.603 \\
\hline Occipital lobe & 124 & 14.3 & 124 & 131 & 17.2 & 130 & 7.63 & 0.007 & 0.571 \\
\hline Gray matter & 70.7 & 9.92 & 71.0 & 69.5 & 9.92 & 69.2 & 0.97 & 0.328 & 0.213 \\
\hline White matter & 53.2 & 7.39 & 53.5 & 61.6 & 7.39 & 61.3 & 23.8 & $<0.0001$ & 1.015 \\
\hline
\end{tabular}

${ }^{a}$ Mean adjusted by covariate.

${ }^{b}$ Covariate used $=$ height.

${ }^{c}$ Covariate used $=$ intracranial volume.

${ }^{d}$ Covariate used $=$ total cerebral tissue volume. 
NSCLP subjects relative to controls had significantly less total CSF, and a significant increase in the amount of cerebral gray matter. Breaking down the volume of cerebral gray matter into surface volume (cortex) and subcortical gray, the increase appears to be accounted for by larger volumes of cerebral cortex as volumes of subcortical gray matter were not different between the two groups. There was no difference between the groups in volume of cerebral white matter. In regard to the cerebellum, when the tissue types where broken down, the volume reduction of this region seen in the subjects with NSCLP was most likely accounted for by a reduction in gray matter volume with sparing of the white matter.

\section{Regions of the cerebrum}

With frontal and parietal lobes combined, the region of the anterior cerebrum showed robust differences between the two groups, with the NSCLP subjects having larger volumes compared with controls. This difference was accounted for by increases in both gray and white matter volume; however, the increase in gray matter volume was robust, whereas the increase in white matter was only at a trend significance level $(P$ $=0.066$ ).

In contrast to the anterior cerebrum, the volume of the posterior cerebrum (temporal and occipital lobe) was significantly smaller in subjects with NSCLP compared with controls. This reduction in total tissue was accounted for primarily by a reduction in white matter volume as the gray matter volume in this region was equal in both groups.

\section{Cerebral lobes}

Evaluation of the individual cerebral lobes showed results similar to the regional analysis above, but with important differences. As expected, both the frontal and parietal lobes were significantly increased in volume in the NSCLP group with elevated gray matter volumes accounting for the majority of the effect. With regard to the posterior section, both the temporal lobe and the occipital lobe showed significant reduction of overall volume in the subjects with NSCLP. However, although the posterior cerebrum measure showed no overall gray matter reduction, when this region was further divided into the temporal lobe and occipital lobe, there were robust reductions of gray matter found in the temporal lobes of the NSCLP group. The temporal lobe also showed significant reductions in white matter volume as well. The occipital lobe showed no differences in gray matter volumes between the two study groups, but did have a robust reduction of volume of white matter in the NSCLP group.

\section{Laterality}

Measures of the cerebral lobes and cerebellum that showed significant group volume discrepancies included frontal lobe gray matter, parietal lobe gray matter, temporal lobe gray and white matter, occipital lobe white matter, and cerebellar gray matter. These regions were evaluated for abnormalities in laterality, comparing right-sided measures to left-sided measures (see Table 3). The enlargement of the anterior regions (frontal and parietal gray matter) did not show significant differences in laterality. However, most of the posterior measures showed significant side by diagnosis interactions with the left-sided volumes being more robustly reduced compared with the right. This finding was the case for temporal lobe gray matter, occipital lobe white matter, and cerebellar gray matter. Although the temporal lobe white matter also showed greater left than right volume reduction, this did not manifest as a significant interaction $(\mathrm{F}=0.19 ; P=0.662)$.

\section{Cleft lip/palate comparison to cleft palate only}

Epidemiologic, phenomenologic, and genetic data support the notion that CLP patients are etiologically distinct from patients with CPO. ${ }^{24}$ Therefore, we believed it would be useful to compare these two subgroups of the NSCLP sample. The same analysis was conducted, as described above, for general measures, regional measures, and cerebral lobes comparing the CLP group $(N=32)$ with the healthy controls $(N=46)$ and again comparing the $\mathrm{CPO}(N=14)$ group with the healthy controls. Results are shown in Table 4. In general, the results of the $\mathrm{CPO}$ versus control analysis are not as robust as the findings in the CLP versus control analysis, and some of this finding may be due to lower power secondary to the small CPO sample of only 14 subjects. Given that preface, both subgroups of the NSCLP sample appeared to have the same pattern of abnormal brain morphology. Both CLP and CPO subjects had significant increases in the anterior cerebral gray matter volumes and concomitant decrements in volumes of the posterior cerebral white matter volumes. The most robust findings for the CLP group were the volume decrements in the cerebellum, occipital lobe, and temporal lobe, in that order. Conversely, the most robust findings for the $\mathrm{CPO}$ group were the decrements in temporal lobe tissue (white matter more than gray matter), and volume increases in the anterior cerebral gray matter, in that order.

\section{DISCUSSION}

\section{General and regional brain measures}

Brain structure in subjects with NSCLP is altered. In all quantitative measures of regional brain volume, and tissue composition, the subjects with NSCLP were significantly different than the control group. With regard to regional brain tissue volume, the NSCLP group had an increase in volume of the anterior portion of the cerebrum with a concomitant decrement in volume of the posterior cerebrum and of the cerebellum. With regard to tissue composition, the increase in anterior regions was accounted for by an increase in cortical gray matter volume. The posterior regions had both white and gray matter decrement in volume with the temporal lobe having significantly decreased white and gray matter, the occipital lobe having decreased white matter, and the cerebellum having decreased gray matter. The temporal lobe appeared to be the region that was most severely affected as it was the only region that had decrement in volume of both gray and white matter. Finally, CSF volume was decreased in the NCSLP group, both 
Table 3

Results of lateralization analysis

\begin{tabular}{|c|c|c|c|c|c|c|}
\hline \multirow{2}{*}{$\begin{array}{l}\text { Regional brain volume } \\
\text { measure }^{a}\end{array}$} & \multirow{2}{*}{$\begin{array}{l}\text { Subjects }(n=46) \\
\text { adjusted means }\end{array}$} & \multirow{2}{*}{$\begin{array}{l}\text { Controls }(n=46) \\
\text { adjusted means }\end{array}$} & \multicolumn{2}{|c|}{ ANCOVA } & \multicolumn{2}{|c|}{$\begin{array}{l}\text { Repeated measures } \\
\text { side by diagnosis }\end{array}$} \\
\hline & & & $\mathrm{F}$ & $P$ & $\mathrm{~F}$ & $P$ \\
\hline Frontal lobe gray matter & & & & & 3.12 & 0.080 \\
\hline Right & 142 & 137 & 6.65 & 0.011 & & \\
\hline Left & 133 & 131 & 2.45 & 0.121 & & \\
\hline Parietal lobe gray matter & & & & & 0.20 & 0.652 \\
\hline Right & 73.2 & 70.7 & 8.25 & 0.005 & & \\
\hline Left & 70.6 & 68.3 & 5.56 & 0.019 & & \\
\hline Temporal lobe gray matter & & & & & 5.60 & 0.020 \\
\hline Right & 77.1 & 78.9 & 4.65 & 0.033 & & \\
\hline Left & 76.9 & 80.0 & 13.1 & 0.0005 & & \\
\hline Temporal lobe white matter & & & & & 0.19 & 0.662 \\
\hline Right & 37.2 & 39.2 & 5.74 & 0.018 & & \\
\hline Left & 37.1 & 39.3 & 8.50 & 0.004 & & \\
\hline Occipital lobe white matter & & & & & 11.61 & 0.001 \\
\hline Right & 25.9 & 28.8 & 11.8 & 0.0009 & & \\
\hline Left & 27.6 & 32.5 & 32.8 & $<0.0001$ & & \\
\hline Cerebellum gray matter & & & & & 4.58 & 0.035 \\
\hline Right & 49.0 & 53.5 & 11.47 & 0.001 & & \\
\hline Left & 49.6 & 55.6 & 17.98 & $<0.0001$ & & \\
\hline
\end{tabular}

ANCOVA, analysis of covariance.

${ }^{a}$ Covariate $=$ total cerebral tissue volume.

${ }^{b}$ Mean adjusted by covariate.

internally (ventricle volume) and externally (CSF on the cortical surface).

Although no other studies have evaluated brain structure in NSCLP, two studies have reported on brain structure in velocardio-facial syndrome. ${ }^{25,26}$ This condition is a genetic syndrome manifested by heart defects, cognitive impairment, and craniofacial abnormalities, including cleft palate. Although these studies showed these patients had significantly smaller total brain size, both studies found a relative increase in the size of the frontal lobe volume, similar to the current findings. Whether or not this phenomenon is related to the oral cleft in this syndrome is unclear, however.

\section{Laterality}

The decrement in the size of the posterior cerebrum in NSCLP subjects was lateralized to the left side. That is, although both sides of the cerebrum and cerebellum were smaller in this group, the left side was more robustly affected than the right. The brain is known to have asymmetry in its representation of cognitive processes. For example, receptive and expressive aspects of language are predominantly represented and more efficiently processed by the left cerebral hemisphere, and in particular, the left temporal lobe. Moreover, there is a substantial amount of literature on the gender differ- ences of cerebral lateralization (for review see Nopoulos and Andreasen and Nopoulos et al.27,28). In general, the male brain appears to be more unilateral (left sided) in its processing of language function, whereas females have more bilateral representation. ${ }^{29}$ This sex difference in the lateralization of language function is most likely related to differences in early brain development, for which it is theorized that the presence of testosterone either promotes the development of the right hemisphere or conversely delays the development of the left hemispheres..$^{30,31}$ It is this particular pattern of male brain development that may be responsible for their vulnerability (compared with females) for neurodevelopmental syndromes, and in particular language disorders such as dyslexia. ${ }^{32}$

Early studies of brain morphology on subjects with language disorders such as dyslexia found that temporal lobe structures such as the planum temporale (PT) have shown "anomalous dominance" in which the normal asymmetry of this region is lost. ${ }^{33-35}$ More recent studies have shown that not just the PT are affected but that the entire left temporal lobe has reduced volume in subjects with dyslexia. ${ }^{36,37}$ In a related group of patients, subjects with the genetic syndrome of XXY (Klinefelter syndrome) have language-based cognitive dysfunction similar to that of dyslexia. ${ }^{38}$ Supportive of the reports of left temporal lobe gray matter reduction in dyslexia, subjects with Klinefelter 
Table 4

Comparison of CLP group, CPO group, and healthy controls

\begin{tabular}{|c|c|c|c|c|c|c|c|}
\hline & \multirow{2}{*}{$\begin{array}{l}\mathrm{CLP}(N=32) \\
\text { adjusted mean }^{a}\end{array}$} & \multirow{2}{*}{$\begin{array}{l}\mathrm{CPO}(N=14) \\
\text { adjusted mean }\end{array}$} & \multirow{2}{*}{$\begin{array}{l}\text { Controls }(n=46) \\
\text { adjusted mean }{ }^{a}\end{array}$} & \multicolumn{2}{|c|}{ CLP vs. control } & \multicolumn{2}{|c|}{$\mathrm{CPO}$ vs. control } \\
\hline & & & & F & $P$ & $\mathrm{~F}$ & $P$ \\
\hline \multicolumn{8}{|l|}{ General measures $^{b}$ (cc's) } \\
\hline Intracranial volume (ICV) & 1,437 & 1,487 & 1,491 & 4.16 & 0.049 & 0.06 & 0.814 \\
\hline Total brain tissue & 1,345 & 1,395 & 1,385 & 2.53 & 0.116 & 0.16 & 0.686 \\
\hline Total CSF & 91.6 & 82.1 & 106 & 2.44 & 0.122 & 4.18 & 0.042 \\
\hline Ventricles & 12.3 & 16.0 & 16.3 & 7.26 & 0.008 & 0.020 & 0.890 \\
\hline Surface CSF & 54.4 & 41.0 & 64.1 & 1.50 & 0.224 & 5.87 & 0.018 \\
\hline Cerebral volume & 1,178 & 1,219 & 1,201 & 1.18 & 0.281 & 0.041 & 0.526 \\
\hline Cerebellar volume & 131 & 139 & 146 & 13.26 & 0.0005 & 1.31 & 0.257 \\
\hline \multicolumn{8}{|l|}{$\begin{array}{l}\text { Tissue segmentation of general } \\
\text { measures }^{c}\left(\mathrm{cc}^{\prime} s\right)\end{array}$} \\
\hline Cerebral gray matter & 712 & 727 & 696 & 2.96 & 0.089 & 4.48 & 0.038 \\
\hline Surface gray matter (cortex) & 656 & 674 & 640 & 3.48 & 0.066 & 6.56 & 0.013 \\
\hline Subcortical gray matter & 55.5 & 52.8 & 56.2 & 0.31 & 0.579 & 5.43 & 0.023 \\
\hline Cerebral white matter & 494 & 496 & 486 & 1.2 & 0.277 & 0.11 & 0.742 \\
\hline Cerebellar gray matter & 96 & 103 & 109 & 17.09 & $<0.0001$ & 2.81 & 0.099 \\
\hline Cerebellar white matter & 36.8 & 37.1 & 35.4 & 0.77 & 0.383 & 0.69 & 0.410 \\
\hline \multicolumn{8}{|l|}{ Regions of the cerebrum ${ }^{d}$ (cc's) } \\
\hline Anterior cerebrum & 737 & 747 & 709 & 9.42 & 0.003 & 6.72 & 0.012 \\
\hline Gray matter & 421 & 433 & 404 & 5.80 & 0.018 & 7.16 & 0.009 \\
\hline White matter & 316 & 314 & 305 & 4.01 & 0.049 & 0.56 & 0.458 \\
\hline Posterior cerebrum & 355 & 363 & 364 & 9.40 & 0.003 & 1.74 & 0.192 \\
\hline Gray matter & 226 & 230 & 226 & 0.01 & 0.927 & 0.44 & 0.509 \\
\hline White matter & 129 & 132 & 138 & 10.75 & 0.001 & 3.92 & 0.05 \\
\hline \multicolumn{8}{|l|}{ Cerebral lobes $^{d}$} \\
\hline Frontal lobe & 465 & 466 & 458 & 5.00 & 0.028 & 1.06 & 0.307 \\
\hline Gray matter & 274 & 280 & 269 & 2.72 & 0.103 & 3.42 & 0.069 \\
\hline White matter & 190 & 186 & 188 & 0.43 & 0.515 & 0.90 & 0.345 \\
\hline Parietal lobe & 264 & 268 & 258 & 7.25 & 0.008 & 6.28 & 0.015 \\
\hline Gray matter & 142 & 146 & 139 & 4.25 & 0.042 & 5.19 & 0.026 \\
\hline White matter & 121 & 122 & 119 & 1.00 & 0.320 & 0.35 & 0.555 \\
\hline Temporal lobe & 229 & 227 & 237 & 10.55 & 0.001 & 12.87 & $<0.001$ \\
\hline Gray matter & 154 & 154 & 158 & 7.14 & 0.009 & 4.34 & 0.041 \\
\hline White matter & 75.2 & 72.6 & 78.6 & 3.38 & 0.069 & 8.61 & 0.004 \\
\hline Occipital lobe & 122 & 129 & 130 & 11.34 & 0.001 & .022 & 0.640 \\
\hline Gray matter & 70.1 & 72.7 & 69.2 & 0.24 & 0.625 & 1.41 & 0.239 \\
\hline White matter & 52.0 & 57.0 & 61.3 & 24.41 & $<0.001$ & 3.16 & 0.081 \\
\hline
\end{tabular}

${ }^{a}$ Mean adjusted by covariate.

${ }^{b}$ Covariate $=$ height.

${ }^{c}$ Covariate $=$ intracranial volume.

${ }^{d}$ Covariate $=$ total cerebral tissue volume. 
syndrome were found to have reductions in the volume of their left temporal lobe gray matter as well. ${ }^{39}$

In reference to the current sample, all the subjects are male. In addition, this sample has been shown to have significant cognitive deficit with a mild decrement in IQ accompanied by specific deficits in language function. ${ }^{14}$ Therefore, the findings of decreased left temporal lobe gray matter volume in this sample of adult males with NSCLP and language deficits are strikingly similar to the brain morphologic findings of other developmental language disorders.

\section{Structure/function relationship}

Are these morphologic changes related to function? The notion that the anterior cerebrum was actually enlarged was somewhat unexpected. One possibility was that it was a compensatory overgrowth, not a primary abnormality. Although the notion that the larger the cerebral volume, the greater the cognitive function, has been documented in normal brains, ${ }^{40}$ there is also evidence to suggest that pathologic enlargement is associated with decreased cognitive function. This finding has been reported in both autism ${ }^{41,42}$ and neurofibromatosis. ${ }^{43,44}$ To investigate this suggestion in the current NSCLP sample, a Spearman's correlation (chosen to decrease the influence of outliers) was calculated between volumes of cerebral regions and IQ, controlling for total brain tissue volume. Table 5 shows the correlations and indicates that the anterior cerebral enlargement was pathologic, with significant inverse correlation with Full Scale IQ (FSIQ) - the larger the anterior cerebrum, the lower the IQ. In addition, there was the reverse finding for the posterior cerebrum - significant positive correlation with FSIQ, indicating that the smaller this region, the lower the FSIQ. These correlations were significant for FSIQ and for Verbal (IQ) but were nonsignificant for Performance IQ (PIQ; non-language-based skills).

\section{Etiology}

The development of the brain and that of the face is intimately entwined. Therefore, it is likely that the abnormalities in brain morphology seen in the current sample are a manifestation of aberrant brain development, just as the facial cleft is a manifestation of aberrant craniofacial development. A previous qualitative study of the MRI scans obtained on the current sample of adult males with NSCLP showed an elevated incidence of a midline brain developmental anomaly, enlarged cavum septi pellucidi (CSP), supporting the notion that the abnormalities seen in the current study are developmental in

\section{Table 5}

Spearman correlations ${ }^{a}$ between regional brain volume measures and intelligence quotients

\begin{tabular}{lccc}
\hline & $\begin{array}{c}\text { Full Scale IQ } \\
\mathrm{r}(P)\end{array}$ & $\begin{array}{c}\text { Performance IQ } \\
\mathrm{r}(P)\end{array}$ & $\begin{array}{c}\text { Verbal IQ } \\
\mathrm{r}(P)\end{array}$ \\
\hline Anterior cerebrum volume & $-0.316(0.034)$ & $-0.199(0.189)$ & $-0.342(0.021)$ \\
Posterior cerebrum volume & $0.409(0.005)$ & $0.169(0.265)$ & $0.456(0.001)$ \\
\hline
\end{tabular}

${ }^{a}$ Controlling for total brain tissue volume. nature. ${ }^{45}$ In addition, the decreased volume of CSF in the NSCLP sample compared with controls would speak against some type of degenerative process, which would instead manifest as regions of decreased tissue volume accompanied by increases in CSF.

The etiology of NSCLP is complex, with both genetic and environmental factors having a role. Genetic epidemiologic studies have shown that several interacting loci, including a major gene, are involved in the etiology of NSCLP, possibly accounting for approximately half of the familial occurrences. ${ }^{46}$ Several candidate genes have been identified as being involved in NSCLP, based on expression, phenotype in transgenic animal, mutations, and linkage/associations in mice or humans. As brain and face development are so closely related, it seems likely that the genetic determinants involved in NSCLP may also be related to formation of abnormal brain structure and function.

As an example of one specific possibility, one particular gene, transforming growth factor (TGF $\beta 3$ ), has been shown to have a strong relationship to the etiology of NSCLP. ${ }^{47,48}$ In addition, TGF $\beta 3$ has a significant role in both early AND late (maturational) brain development. TFG $\beta 3$ proteins have been shown to play an important role in neuronal development in both invertebrates and vertebrates..$^{49}$ With regard to early brain development, these proteins are involved in proliferation and dorsal-ventral patterning. Clearly, the abnormalities in brain morphology outlined above have a distinct pattern consistent with abnormal dorsal-ventral tissue distribution. In addition, TGF $\beta 3$ has been shown to be involved in a late step in the pathways that specify asymmetry in the embryo. ${ }^{50}$ Once again, the abnormal brain morphology demonstrated in this study of adults with NSCLP shows significant asymmetry with the leftsided regions being more severely affected than right-sided regions. Finally, a very recent report outlines the key role that TGF $\beta 3$ plays in neurogenesis and apoptosis, mechanisms directly linked to etiology of neuronal tissue morphology. ${ }^{51}$

In summary, subjects with NSCLP show significant alterations in brain morphology. Moreover, these changes are directly related to cognitive function. These findings highlight the intimate relationship between growth and development of the brain and that of the face. Aberrant craniofacial development may manifest in brain abnormalities and vice versa, suggesting that facial clefting may be the result of a primary problem in facial growth, a primary problem in brain growth, or both.

\section{Acknowledgments}

This study was supported by March of Dimes Basil O'Connor Starter Scholar Award grant 5-FY97-0120; NIMH grants MH31593, MH40856, and MHCRC 43271; The Nellie Ball Trust Fund, Iowa State Bank and Trust Company, Trustee; and a Research Scientist Award, MH00625.

\section{References}

1. Jones MC. Etiology of facial clefts: prospective evaluation of 428 patients. Cleft Palate J 1988;25:16-20. 
2. Richman LC. Cognitive patterns and learning disabilities in cleft palate children with verbal deficits. J Speech Hear Res 1980;23:447-456.

3. Kommers M, Sullivan M. Written language skills of children with cleft palate. Cleft Palate J 1979;16:81-85.

4. Richman LC, Eliason M. Disorders of communication, developmental language disorders and cleft palate. In: Walker CE, Roberts MC, editors. Handbook of child clinical psychology - revised. New York: John Wiley \& Sons, 1993.

5. Richman LC, Eliason MJ, Lindgren SD. Reading disability in children with cleft lip and/or palate. Cleft Palate J 1988;25:21-25.

6. Estes R, Morris H. Relationship among intelligence, speech proficiency, and hearing sensitivity in children with cleft palates. Cleft Palate J 1970;7:763-773.

7. Sak RJ, Ruben RJ. Effects of recurrent middle ear effusion in preschool years on language and learning. J Dev Behav Pediatr 1982;3:7-11.

8. Ventry IM. Effects of conductive hearing loss: fact or fiction. J Speech Hear Disord 1980;45:143-156.

9. Hubbard TW, Paradise JL, McWilliams BJ, Elster BA, Tylor FH. Consequences of unremitting middle-ear disease in early life. Otologic, audiologic, and developmental findings in children with cleft palate. N Engl J Med 1985;3312:1529-1534.

10. Sperber G. First year of life: prenatal craniofacial development. Cleft Palate Craniofac J 1992;29:109-111.

11. Kjaer I. Human prenatal craniofacial development related to brain development under normal and pathologic conditions [review]. Acta Ondontol Scand 1995;53: $135-143$.

12. Nopoulos P, Berg S, Canady J, Richman L, Van Demark D, Andreasen NC. Abnormal brain morphology in adult males with isolated clefts of the lip and/or palate: a preliminary analysis. Cleft Palate Craniofac J 2000;37:441-446.

13. Wechsler D. Wechsler Adult Intelligence Scale - Revised. Manual. Cleveland, OH: The Psychological Corporation, 1981.

14. Nopoulos P, Berg S, VanDemark D, Richman L, Canady J, Andreasen NC. Cognitive dysfunction in adult males with non-syndromic clefts of the lip and/or palate. Neuropsychologia. In press.

15. Andreasen NC, Cizadlo T, Harris G, Swayze V, O'Leary DS, Cohen G, Ehrhardt J, Yuh WTC. Voxel processing techniques for the antemortem study of neuroanatomy and neuropathology using magnetic resonance imaging. J Neuropsychiatry Clin Neurosci 1993;5:121-130.

16. Andreasen NC, Cohen G, Harris G, Cizadlo T, Parkkinen J, Rezai K, Swayze VW Image processing for the study of brain structure and function: Problems and programs. J Neuropsychiatry Clin Neurosci 1992;4:125-133.

17. Andreasen NC, Harris G, Cizadlo T. Techniques for measuring sulcal/gyral patterns in the brain as visualized through MR scanning: BRAINPLOT and BRAINMAP. Proc Natl Acad Sci U S A 1994;90:93-97.

18. Cohen G, Andreasen NC, Alliger R, Arndt S, Kuan J, Yuh WT, Ehrhardt J. Segmentation techniques for the classification of brain tissue using magnetic resonance imaging. Psychiatry Res 1992;45:33-51.

19. Talairach J, Tournoux P. Co-planar stereotaxic atlas of the human brain. New York: Thieme Medical Publishers, 1988.

20. Andreasen NC, Rajaprabhakaran R, Cizadlo T, Arndt S, Swayze VW Jr, Flashman L, O'Leary DS, Ehrhardt J, Yuh WTC. Automated atlas-based dissection of the human brain from MR images. J Comput Assist Tomogr 1994;20:98-106.

21. Collins DL, Neelin P, Peters TM, Evans AC. Automatic 3D intersubject registration of MR volumetric data in standardized Talairach space. J Comput Assist Tomogr 1994;18:192-205.

22. Harris G, Andreasen NC, Cizadlo T, Bailey JM, Bockholt HJ, Magnotta VA, Arndt S Improving tissue segmentation in MRI: a three-dimensional multispectral discriminant analysis method with automated training class selection. J Comput Assist Tomogr 1999;23:144-154.

23. Cohen J. Statistical power analysis for the behavioral sciences. Hillsdale, NJ: Lawrence Erlbaum Associates, 1988.

24. Jones MC. Facial clefting: etiology and developmental pathogenesis. Clin Plast Surg 1993;20:599-606.

25. Eliez S, Schmitt E, White C, Reiss A. Children and adolescents with Velocardiofacial Syndrome: a volumetric MRI study. Am J Psychiatry 2000;157:409-415.

26. Kates WR, Burnett CP, Jabs EW, Rutberg J, Murphy AM, Grados M, Geraghty M Kaufmann WE, Pearlson GD. Regional cortical white matter reductions in velocardiofacial syndrome: a volumetric MRI analysis. Biol Psychiatry 2001;49:677-684.

27. Nopoulos P, Andreasen NC. Gender differences in neuroimaging. In: Leibenluft E, editor. Gender differences in mood and anxiety disorders. From bench to bedside. Washington, DC: American Psychiatric Press, Inc., 1999:1-24.
28. Nopoulos P, Schultz S, Andreasen NC. Brain, and behavior. In: Wallis L, editor. Textbook of women's health. Lippincott-Raven: Philadelphia, 1998:795-802.

29. Shaywitz B, Shaywitz S, Pugh K, Constable R, Skudlarski P, Fulbright R, Bronen R, Fletcher R, Shankweller D, Katz L, Gore J. Sex differences in the functional organization of the brain for language. Nature 1995;373:607-609.

30. de Lacoste M, Horvath D, Woodward D. Possible sex differences in the developing human fetal brain. J Clin Exp Neuropsychol 1991;13:831-846.

31. Bear D, Schiff D, Saver J, Greenberg M, Freeman R. Quantitative analysis of cerebral asymmetries. Arch Neurol 1986;43:598-603.

32. Geschwind N, Galaburda AM. Cerebral lateralization. Biological mechanisms, associations, and pathology: I. A hypothesis and a program for research. Arch Neurol $1985 ; 42: 428-459$.

33. Galaburda AM, Sherman GF, Rosen GD, Aboitiz F, Geschwind N. Developmental dyslexia: four consecutive patients with cortical anomalies. Ann Neurol 1985;18: 222-233.

34. Leonard CM, Voeller KKS, Lonbardino LJ, Morris MK, Hynd GW, Alexander AW, Andersen HG, Garofalakis M, Honeyman JC, Mao J, Agee F, Staab EV. Anomalous cerebral structure in dyslexia revealed with magnetic resonance imaging. Arch Neurol 1993;50:461-469.

35. Hynd GW, Semrud-Clikeman M. Dyslexia and brain morphology. Psychol Bull 1989;106:447-482.

36. Eliez S, Rumsey JM, Giedd JN, Schmitt JE, Patwardhan AJ, Reiss AL. Morphological alteration of temporal lobe gray matter in dyslexia: an MRI study. J Child Psychol Psychiatry 2000;41:637-644.

37. Dalby MA, Elbro C, Stodkilde-Jorgensen H. Temporal lobe asymmetry and dyslexia: an in vivo study using MRI. Brain Lang 1998;62:51-69.

38. Geschwind DH, Gregg J, Boone K, Karrim J, Pawlikowska-Haddal A, Rao E, Ellison J, Ciccodicola A, D’Urso M, Woods R, Rappold GA, Swerdloff R, Nelson SF. Klinefelter's syndrome as a model of anomalous cerebral laterality: testing gene dosage in the $\mathrm{X}$ chromosome pseudoautosomal region using a DNA microarray. Dev Genet 1998;23:215-229.

39. Patwardhan AJ, Eliez S, Bender B, Linden MG, Reiss AL. Brain morphology in Klinefelter syndrome: extra X chromosome and testosterone supplementation. Neurology 2000;54:2218-2223.

40. Andreasen N, Flaum M, Swayze V, O'Leary D, Alliger R, Cohen G, Ehrhardt J, Yuh W. Intelligence and brain structure in normal individuals. Am J Psychiatry 1993;150: $130-134$

41. Piven J, Arndt S, Bailey J, Havercamp S, Andreasen NC, Palmer P. An MRI study of brain size in autism. Am J Psychiatry 1995;152:1145-1149.

42. Piven J, Arndt S, Bailey J, Andreasen NC. Regional brain enlargement in autism: an MRI study. J Am Acad Child Adolesc Psychiatry 1996;35:530-536.

43. Said SM, Yeh TL, Greenwood RS, Whitt JK, Tupler LA, Krishnan KR. MRI morphometric analysis and neuropsychological function in patients with neurofibromatosis. Neuroreport 1996;7:1941-1944.

44. Moore BD III, Slopis JM, Jackson EF, De Winter AE, Leeds NE. Brain volume in children with neurofibromatosis type 1: relation to neuropsychological status. Neurology 2000;54:914-920.

45. Nopoulos P, Berg S, Canady J, Richman L, VanDemark D, Andreasen NC. Increased incidence of a midline brain anomaly in adult males with nonsyndromic clefts of the lip and/or palate. J Neuroimag 2001;11:1-7.

46. Christensen K, Mitchell LE. Familial recurrence-pattern analysis of nonsyndromic isolated cleft palate: a Danish registry study. Am J Med Genet 1996;58:182-190.

47. Fitzpatrick DR, Denhez F, Kondaiah P, Akhurst RJ. Differential expression of TGFB isoforms in murine palatogenesis. Development 1990;109:585-595.

48. Lidral AC, Romitti PA, Basart AM, Doetschman T, Leysens NJ, Daack-Hirsch S, Semina EV, Johnson LR, Machida J, Burds A, Parnell TJ, Rubenstein JLR, Murray JC. Association of MSX1 and TGFB3 with nonsyndromic clefting in humans. Am J Hum Genet 1998;63:557-568.

49. Kingsley DM. The TGF-beta superfamily: new members, new receptors, and new genetic tests of function in different organisms. Genes Dev 1994;8:133-146.

50. King T, Brown NA. Embryonic asymmetry: left TGFB at the right time? Curr Biol 1997;7:212-215.

51. Hagedorn L, Floris J, Suter U, Sommer L. Autonomic neurogenesis and apoptosis are alternative fates of progenitor cell communities induced by TGFbeta. Dev Biol 2000;228:57-72. 